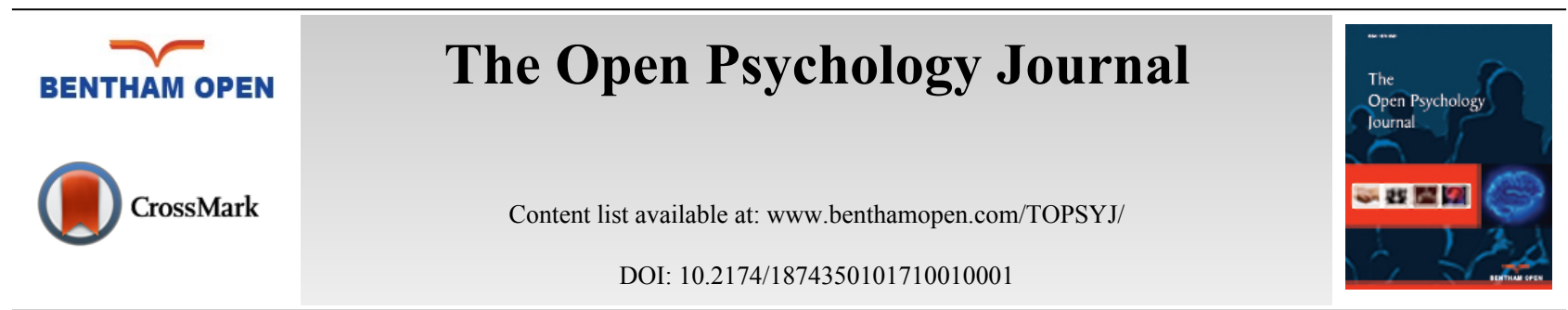

RESEARCH ARTICLE

\title{
Concurrent Validity of the Computer-assisted Structured Diagnostic Interview (CASDI) for Children and Adolescents Aged 8-18 Years Old
}

\author{
George Giannakopoulos*
}

National and Kapodistrian University of Athens, Athens, Greece

Received: October 13, 2016

Revised: January 01, 2017

Accepted: January 03, 2017

\section{Abstract: \\ Background:}

Making a diagnosis of a particular mental disorder in children and adolescents can be a challenging or overwhelming task for clinicians and researchers, with each step of a DSM-5 based diagnostic procedure necessitating a practical use of time to gather appropriate information.

\section{Objective:}

To assess concurrent validity of the Computer-Assisted Structured Diagnostic Interview (CASDI), a newly devised, fully structured interview which encompasses categorical and dimensional approaches and automatically navigates the interviewer, through computerized decision trees (algorithms), in a specified probing system.

\section{Method:}

A total of 258 children and adolescents (46.51\% boys) aged $8-18$ years (Mean \pm SD: $12.66 \pm 2.73$ ) and their parents were recruited from a community sample. For each pair of child-parent, the child and one parent were interviewed separately by an interviewer using the CASDI and by a second blind interviewer using the DSM-5 Pediatric Diagnostic Interview one week after the CASDI administration. Validity indicators (sensitivity, specificity, positive and negative likelihood ratios, and positive and negative predictive values for 12-month diagnoses were calculated.

\section{Results:}

The CASDI had sensitivity above 70\% for Neurodevelopmental Disorders, Schizophrenia Spectrum and Other Psychotic Disorders, Depressive Disorders, Anxiety Disorders, Obsessive-Compulsive and Related Disorders, Trauma- and Stressor-Related Disorders, Somatic Symptom and Related Disorders, Feeding and Eating Disorders, Elimination Disorders, Sleep-Wake Disorders, Gender Dysphoria, Disruptive, Impulse-Control, and Conduct Disorders, Substance-Related and Addictive Disorders and below 50\% for Bipolar and Related Disorders and Dissociative Disorders.

\section{Conclusion:}

The observed validity indicators suggest that the CASDI can be potentially used to accurately diagnose child and adolescent mental health disorders for research and clinical purposes. Its use in special populations, such as hospitalized or institutionalized children and adolescents, deserves further study.

Keywords: Adolescents, Children, DSM-5, Sensitivity, Specificity, Structured Interviews, Validity.

\footnotetext{
* Address correspondence to this author at the National and Kapodistrian University of Athens, 124B V. Sophias Av, Athens 11526 Greece; Tel: 00302107796673; Fax: 00302109714294; E-mails: ggiannak@med.uoa.gr, giannakopoulos.med@gmail.com
} 


\section{INTRODUCTION}

Making a diagnosis of a particular mental disorder in children and adolescents can be a challenging or overwhelming task for clinicians or researchers who are less experienced or have to complete their assessment within a limited time frame. Such an evaluation can seem impossible, especially if a clinician intends to make a well-supported DSM-5 [1] diagnosis. Each step of a DSM-5 based diagnostic procedure with a child and his or her caregivers (i.e., examining if a child's clinical presentation fulfills the specific symptom-based diagnostic criteria, judging if the symptoms are not caused by other diagnoses or stressors and evaluating the impairment caused by these symptoms on a child's functioning) necessitates a practical use of time to gather appropriate information [2].

The categorical model of mental illness preserved by DSM-5, in which a person does or does not have a mental illness, is widely recognized for its diagnostic reliability (i.e., the ability of different clinicians to agree on the diagnosis of a particular mental disorder for a particular person) [3]. However, diagnostic validity of the categorical model (i.e. the ability of clinicians to make an accurate diagnosis) is considered limited [3,4]. The dimensional model aims to improve the variability and validity of psychiatric diagnoses through measures that quantify and personalize the diagnostic criteria for a particular person according to his or her own subjective experience of core symptoms and with reference to normative data of clinical or community samples. These measures include short symptom statements that a child or his/her caregiver assesses, often with a five-point scale of symptom levels. Beyond identification of presenting problems, these measures have the potential benefit of assessing treatment response and progress toward recovery through measurable outcomes. However, these measures are not designed to indicate the presence or absence of a specific diagnosis since they assess dimensions of symptomatology rather than fulfillment of diagnostic criteria [5, 6].

As far as child and adolescent mental health assessment is concerned, an additional debate is whether children provide reliable or valid clinical information during diagnostic interviews, even though researchers and clinicians generally agree that it is beneficial to hear a child's account of his or her presenting problems. In fact, latest research has documented that children can contribute relevant, clinically useful, valid information during clinical psychological assessments [7].

In the context of these challenges and limitations, we developed a fully structured interview in the Greek language, the Computer-Assisted Structured Diagnostic Interview (CASDI), which encompasses categorical and dimensional approaches and automatically navigates the interviewer, through computerized decision trees (algorithms), in a specified probing system including: (a) screening questions regarding severity of most common symptoms during the last 12 months, (b) follow-up questions measuring impairment due to reported common symptoms of at least mild severity and, when appropriate, (c) symptom questions regarding severity and duration in the diagnostic criteria of child and adolescent mental health disorders. A self-response interview (CASDI 8-18) for children and adolescents aged 8-18 years and a proxy interview (CASDI 6-18) for caregivers of youths aged 6-18 years are available. The duration of the interview with each informant (child or caregiver) can vary from 30 minutes (subject with no psychiatric diagnosis) to 180 minutes (subject with three comorbid diagnoses).

After an initial five-minute phase of introducing interviewer to the informant and listening to the informant's uninterrupted speech about reason of referral, the interview proceeds to 15 open-ended questions about the history of the current illness, with a focus on the "why now?" of the presentation and precipitating events, psychiatric history of the child, past medical history, family history, developmental and social history. Beyond valuable qualitative information that is yielded in the above phases of the interview, this time builds the alliance and allows the interviewer to understand much of the mental status of the child. Also, 12 questions regarding child's functional impairment elicit a response from the informant in a five-point rating scale of impairment level (None-Slight-Mild-Moderate-Severe). Additionally, in the proxy interview, a total of 21 questions assessing symptoms of specific learning disorders is also included. This section is expected to be completed in 10-15 minutes.

A total of 343 screening questions, follow-up impairment questions and severity/duration symptom questions for each of the DSM-5 categories of mental disorders-experienced by children and adolescents and reported by themselves or their caregivers-follow next. This set of questions constitutes the core diagnostic section of the CASDI. All questions intend to elicit a response from the informant in a five-point rating scale of symptom severity or impairment levels (None-Slight-Mild-Moderate-Severe), with the exception of responses to questions measuring symptom duration that are coded categorically. Information about diagnostic criteria that are observed rather than elicited, as in the case of disorganized speech, is categorically coded based on interviewer's responses (Yes-No). Additionally, the interviewer reports (Yes-No-Unsure) if any symptoms are attributable to another medical condition or to the physiological effects of 
a substance/medication. Diagnostic categories and specific diagnoses reviewed through the CASDI questions are presented in Table 1 with reference to DSM-5 and respective ICD-10 codes. In case that criteria for the abovementioned diagnoses are not fully met, the CASDI prompts the interviewer to consider alternative diagnoses, mainly either unspecified/provisional disorders that need to be excluded or reassessed in a later time or diagnoses that require more systematic assessment, such as individualized, standardized intelligence testing or laboratory tests. These alternative diagnoses are presented in Table 2.

The interview with the child or the caregiver ended with a two-minute set of follow-up open-ended questions asking whether the CASDI questions addressed informant's major concerns, if there is anything important the CASDI missed or anything that the interviewer should know about to better understand what the informant is going through.

The last section of the CASDI includes a set of questions for interviewer-rating only to be made after the completion of interviewing the child or the caregiver. Findings from the mental status examination regarding child's appearance, behavior, speech, emotion, thought process, thought content, cognition and intellectual resources, and judgement and insight are categorically ( $Y e s-\mathrm{No}$ ) coded here. Last, the interviewer is asked to mark, if appropriate, the presence of any conditions and problems from a selected list provided by the DSM-5 [1]. These conditions include mainly psychosocial and environmental problems that may be a focus of clinical attention or that may otherwise affect the diagnosis, course, prognosis, or treatment of a child's mental disorder. Coding these conditions and problems aims to draw attention to additional issues that are encountered in clinical practice and it is useful to be documented by clinicians.

Separate scores and diagnoses by child and parental reports are generated. The CASDI automatically informs interviewer during online completion about the mental disorders (coded according to ICD-10) for which the DSM-5 diagnostic criteria are fulfilled, based on children's and parents' reports. If a diagnosis is reported as being present by either the child or the parent, then it is counted as being present for the purpose of making a joint diagnosis.

The present study aimed to assess concurrent validity of the CASDI, using as a gold standard the clinical diagnoses formulated using the DSM-5 diagnostic criteria and based on the DSM-5 Pediatric Diagnostic Interview [8].

\section{METHODS}

\section{Participants and Procedure}

This study was conducted in 2016. The sampling was performed to take into account distribution of the target population by age. The target population was children and adolescents aged 8 to18. A sample size of 200 subjects was considered necessary to detect at least one case of diagnostic categories that are relatively rare (prevalence below $1 \%$ ) in community samples. A recruitment rate of approximately $70 \%$ was expected, so the initial sample size was set at 285 children and adolescents. Children and their parents were recruited from municipal extracurricular educational and athletic activities facilities in Athens, Greece. Inclusion criteria were adequate knowledge of the Greek language. Written informed consent from parents and oral assent from children and adolescents were obtained.

For each pair of child-parent, the child and one parent were interviewed separately by an interviewer using the CASDI and by a second blind interviewer using the DSM-5 Pediatric Diagnostic Interview one week after the CASDI administration. A team of four interviewers with varied experience in clinical interviews with children and adolescents carried out the project. Most interviews $(84.88 \%)$ where completed in one session.

The average duration of the CASDI was 90 minutes, varying from 30 minutes (child with no psychiatric diagnosis) to 180 minutes (subject with Neurodevelopmental Disorder and Trauma- and Stressor-Related Disorder diagnoses). Most interviews (80\%) where completed in one session. Separate and joint diagnoses by child and parental report were generated. For the purpose of the present analysis, joint diagnoses were used.

\section{Data Analysis}

Analyses were conducted concerning full data without missing values. The concurrent validity was studied for 12month diagnoses in terms of DSM-5 diagnostic categories. Validity indicators and the formulas by which they were calculated were as follows (Table $\mathbf{3}$ ):

\section{Sensitivity}

Probability that a CASDI result will be positive when the DSM-5 Pediatric Interview diagnosis is present. 


$$
\text { Sensitivity }=\frac{a}{a+b}
$$

\section{Specificity}

Probability that a CASDI result will be negative when the DSM-5 Pediatric Interview diagnosis is not present.

$$
\text { Specificity }=\frac{d}{c+d}
$$

\section{Positive Likelihood Ratio}

Ratio between the probability of a positive CASDI result given the presence of the DSM-5 Pediatric Interview diagnosis and the probability of a positive CASDI result given the absence of the DSM-5 Pediatric Interview diagnosis.

$$
\text { Positive likelihood ratio }=\frac{\text { Sensitivity }}{100-\text { Specificity }}
$$

\section{Negative Likelihood Ratio}

Ratio between the probability of a negative CASDI result given the presence of the DSM-5 Pediatric Interview diagnosis and the probability of a negative CASDI result given the absence of the DSM-5 Pediatric Interview diagnosis.

$$
\text { Positive likelihood ratio }=\frac{100-\text { Sensitivity }}{\text { Specificity }}
$$

\section{Positive Predictive Value}

Probability that the DSM-5 Pediatric Interview diagnosis is present when the CASDI result is positive.

$$
\text { Positive predictive value }=\frac{a}{a+c}
$$

\section{Negative Predictive Value}

Probability that the DSM-5 Pediatric Interview diagnosis is not present when the CASDI result is negative.

$$
\text { Negative predictive value }=\frac{d}{b+d}
$$

Sensitivity, specificity, positive and negative predictive value were expressed as percentages for ease of interpretation. Their confidence intervals were "exact" Clopper-Pearson confidence intervals. Confidence intervals for the likelihood ratios were calculated using the "Log method" [9]. Also, the Cohen's unweighted Kappa coefficient [10] was calculated to allow comparisons with other studies. All responses from the diagnostic section of the CASDI were automatically coded and analyzed as numerical data using SPSS statistical software (version 17.0).

\section{RESULTS}

A total of 258 (i.e. $90.53 \%$ recruitment rate) children and adolescents ( $46.51 \%$ boys) aged $8-18$ years (Mean \pm SD: $12.66 \pm 2.73$ ) and their parents completed the CASDI. Close to half the sample had an intermediate level of family affluence $(45.35 \%$ ), while $36.43 \%$ had low level and $18.22 \%$ had high level of family affluence.

The CASDI generated in average 1.5 diagnoses per participating child, while the member of the team (an experienced child and adolescent psychiatrist) who conducted DSM-5 Pediatric Diagnostic Interview formulated 1.2 diagnoses per subject.

The validity indicators of the CASDI in diagnosing specific 12-month DSM-5 diagnostic categories are shown in Table 3. The CASDI had sensitivity above $70 \%$ for Neurodevelopmental Disorders, Schizophrenia Spectrum and Other Psychotic Disorders, Depressive Disorders, Anxiety Disorders, Obsessive-Compulsive and Related Disorders, Trauma- 
and Stressor-Related Disorders, Somatic Symptom and Related Disorders, Feeding and Eating Disorders, Elimination Disorders, Sleep-Wake Disorders, Gender Dysphoria, Disruptive, Impulse-Control, and Conduct Disorders, SubstanceRelated and Addictive Disorders and below 50\% for Bipolar and Related Disorders and Dissociative Disorders.

\section{DISCUSSION}

The CASDI was well accepted by both children and parents and there were no refusals to participate. More diagnoses per patient were formulated according to the DSM-5 Pediatric Interview than the CASDI, which is in agreement with the literature on fully structured diagnostic interviews [11].

In consistency with previous research [12 - 18], sensitivity of the CASDI was high (above 70\%) for the great majority of the diagnostic categories. The low sensitivity rates (below 50\%) of bipolar and related disorders have been also reported in other studies [16 - 18]. The lack of mechanisms to verify the veracity of the information regarding manic symptoms and the need of clinical judgment have been suggested as possible reasons for low sensitivity in diagnosing bipolar disorders through structured interviews [17]. Moreover, the CASDI showed low sensitivity in diagnosing dissociative disorders. The nature of dissociative symptoms and the limited capability of children and parents to provide this type of information based on Likert scale responses to structured questions may explain this low sensitivity rate.

It should be noted here that the CASDI required impairment of at least mild severity in order to diagnose a specific mental health disorder in children who attained symptom thresholds for this specific disorder. Although this requirement may decrease diagnostic thresholds, there is some evidence that a requirement of severe impairment criteria miss about half of the clinically referred cases of children who eventually remain undiagnosed and possibly untreated [19].

Standardization of data collection, widening and deepening the investigation field of the interviewer, standardization of the communication between different professionals, and reducing clinician bias are some of the advantages found in the CASDI as well as previously reported fully structured diagnostic interviews. Moreover, the additive value of the CASDI compared with other structured interviews is the integration of dimensional model of mental illness into the long-standing categorical model of psychiatric diagnostic interviews. By quantifying and personalizing the diagnostic criteria for a particular child and his or her caregiver according to their own subjective experience of core symptoms and the clinical judgment, when needed, and by employing computerized decision trees (algorithms), the CASDI seem to offer a convenient, easy to use and developmentally acceptable diagnostic procedure yielding a valid diagnosis.

Table 1. DSM-5 diagnostic categories and diagnoses reviewed in the CASDI.

\begin{tabular}{|c|c|c|c|c|c|c|}
\hline Diagnostic Category & $\begin{array}{l}\text { Screening } \\
\text { Questions } \\
\end{array}$ & $\begin{array}{l}\text { Follow-up } \\
\text { Questions } \\
\end{array}$ & $\begin{array}{l}\text { Symptom } \\
\text { Questions }\end{array}$ & Diagnosis & $\begin{array}{l}\text { DSM-5 } \\
\text { Code }\end{array}$ & $\begin{array}{c}\text { ICD-10 } \\
\text { Code }\end{array}$ \\
\hline \multirow[t]{5}{*}{ Neurodevelopmental Disorders } & \multirow[t]{5}{*}{2} & 2 & 17 & Autism Spectrum Disorder & 299.00 & F84.0 \\
\hline & & \multirow[t]{4}{*}{1} & \multirow[t]{4}{*}{18} & $\begin{array}{l}\text { Attention-Deficit/Hyperactivity Disorder, } \\
\text { presentation: }\end{array}$ & & \\
\hline & & & & Combined & 314.01 & F90.2 \\
\hline & & & & Predominantly inattentive & 314.00 & F90.0 \\
\hline & & & & Predominantly hyperactive/impulsive & 314.01 & F90.1 \\
\hline $\begin{array}{l}\text { Schizophrenia Spectrum and } \\
\text { Other Psychotic Disorders }\end{array}$ & 4 & 2 & 5 & Schizophrenia & 295.90 & F20.9 \\
\hline \multirow[t]{2}{*}{ Bipolar and Related Disorders } & \multirow[t]{2}{*}{1} & \multirow[t]{2}{*}{4} & 13 & Bipolar I Disorder & $296 . x$ & F31.x \\
\hline & & & 13 & Bipolar II Disorder & 296.89 & F31.81 \\
\hline \multirow[t]{2}{*}{ Depressive Disorders } & 3 & 2 & 10 & Major Depressive Disorder & $296 . x$ & F3x.xx \\
\hline & 1 & 2 & 8 & Disruptive Mood Dysregulation Disorder & 296.99 & F34.8 \\
\hline \multirow[t]{3}{*}{ Anxiety Disorders } & \multirow[t]{3}{*}{7} & \multirow[t]{3}{*}{1} & 3 & Specific Phobia & 300.29 & $\mathrm{~F} 40.2 \mathrm{xx}$ \\
\hline & & & 16 & Panic Disorder & 300.01 & F41.0 \\
\hline & & & 6 & Generalized Anxiety Disorder & 300.02 & F41.1 \\
\hline \multirow{4}{*}{$\begin{array}{l}\text { Obsessive-Compulsive and } \\
\text { Related Disorders }\end{array}$} & \multirow[t]{4}{*}{2} & \multirow[t]{4}{*}{1} & 4 & Obsessive-Compulsive Disorder & 300.03 & F42 \\
\hline & & & \multirow[t]{3}{*}{4} & Body-Focused Repetitive Behaviors & & \\
\hline & & & & Trichotillomania (Hair-Pulling Disorder) & 312.39 & F63.3 \\
\hline & & & & Excoriation (Skin-Picking) Disorder & 698.4 & L98.1 \\
\hline
\end{tabular}




\begin{tabular}{|c|c|c|c|c|c|c|}
\hline Diagnostic Category & $\begin{array}{l}\text { Screening } \\
\text { Questions }\end{array}$ & $\begin{array}{l}\text { Follow-up } \\
\text { Questions }\end{array}$ & $\begin{array}{l}\text { Symptom } \\
\text { Questions }\end{array}$ & Diagnosis & $\begin{array}{l}\text { DSM-5 } \\
\text { Code }\end{array}$ & $\begin{array}{c}\text { ICD-10 } \\
\text { Code }\end{array}$ \\
\hline \multirow{3}{*}{$\begin{array}{l}\text { Trauma- and Stressor-Related } \\
\text { Disorders }\end{array}$} & \multirow[t]{3}{*}{3} & \multirow[t]{3}{*}{2} & \multirow[t]{2}{*}{20} & Posttraumatic Stress Disorder & 309.81 & F43.10 \\
\hline & & & & Acute Stress Disorder & 308.3 & F43.0 \\
\hline & & & 5 & Reactive Attachment Disorder & 318.89 & F94.1 \\
\hline \multirow[t]{2}{*}{ Dissociative Disorders } & \multirow[t]{2}{*}{2} & \multirow[t]{2}{*}{1} & 2 & Dissociative Amnesia & 300.12 & F44.0 \\
\hline & & & 3 & Depersonalization/Derealization Disorder & 300.6 & F48.1 \\
\hline \multirow{2}{*}{$\begin{array}{l}\text { Somatic Symptom and Related } \\
\text { Disorders }\end{array}$} & \multirow[t]{2}{*}{2} & \multirow[t]{2}{*}{2} & 5 & Somatic Symptom Disorder & 300.82 & F45.1 \\
\hline & & & 4 & Illness Anxiety Disorder & 300.7 & F45.21 \\
\hline \multirow[t]{2}{*}{ Feeding and Eating Disorders } & \multirow[t]{2}{*}{2} & \multirow[t]{2}{*}{1} & 7 & Anorexia Nervosa & 307.1 & F50.0x \\
\hline & & & 5 & Avoidant/Restrictive Food Intake Disorder & 307.59 & F50.8 \\
\hline \multirow[t]{2}{*}{ Elimination Disorders } & \multirow[t]{2}{*}{1} & & 2 & Enuresis & 307.6 & F98.0 \\
\hline & & & 2 & Encopresis & 307.7 & F98.1 \\
\hline \multirow[t]{3}{*}{ Sleep-Wake Disorders } & \multirow[t]{3}{*}{4} & & 3 & Insomnia Disorder & 307.42 & F51.01 \\
\hline & & & 4 & Hypersomnolence Disorder & 307.44 & F51.11 \\
\hline & & & 5 & Restless Legs Syndrome & 333.94 & G25.81 \\
\hline \multirow[t]{2}{*}{ Gender Dysphoria } & \multirow[t]{2}{*}{1} & \multirow[t]{2}{*}{2} & 9 & Gender Dysphoria in Children & 302.6 & F64.2 \\
\hline & & & 6 & Gender Dysphoria in Adolescents & 302.85 & F64.1 \\
\hline \multirow{3}{*}{$\begin{array}{l}\text { Disruptive, Impulse-Control, } \\
\text { and Conduct Disorders }\end{array}$} & \multirow[t]{3}{*}{2} & \multirow[t]{3}{*}{1} & 9 & Oppositional Defiant Disorder & 313.81 & F91.3 \\
\hline & & & 10 & Intermittent Explosive Disorder & 312.34 & F63.81 \\
\hline & & & 17 & Conduct Disorder & $312.8 x$ & F91.x \\
\hline \multirow[t]{3}{*}{$\begin{array}{l}\text { Substance-Related and } \\
\text { Addictive Disorders }\end{array}$} & \multirow[t]{3}{*}{4} & \multirow[t]{3}{*}{1} & 14 & Alcohol Use Disorder & $\begin{array}{l}305.00 \\
303.90\end{array}$ & F10.x0 \\
\hline & & & 14 & Cannabis Use Disorder & $\begin{array}{l}305.20 \\
304.30\end{array}$ & $\mathrm{~F} 12 . \mathrm{x} 0$ \\
\hline & & & 14 & Tobacco Use Disorder & 305.1 & \begin{tabular}{|l} 
Z72.0. \\
F17.200
\end{tabular} \\
\hline
\end{tabular}

Table 2. Alternative diagnoses considered in the CASDI.

\begin{tabular}{|c|c|c|c|}
\hline Diagnostic Category & Diagnosis & DSM-5 Code & ICD-10 Code \\
\hline \multirow[t]{25}{*}{ Neurodevelopmental Disorders } & Intellectual Disability (Intellectual Developmental Disorder), current severity & & \\
\hline & Mild & 317 & F70 \\
\hline & Moderate & 318.0 & F71 \\
\hline & Severe & 318.1 & F72 \\
\hline & Profound & 318.2 & F73 \\
\hline & Global Developmental Delay & 315.8 & F88 \\
\hline & Unspecified Intellectual Disability (Intellectual Developmental Disorder) & 319 & F79 \\
\hline & Speech Sound Disorder & 315.39 & F80.0 \\
\hline & Childhood-Onset Fluency Disorder (Stuttering) & 315.35 & F80.81 \\
\hline & Social (Pragmatic) Communication Disorder & 315.39 & F80.89 \\
\hline & Unspecified Communication Disorder & 307.9 & F80.9 \\
\hline & Specific Learning Disorder & & \\
\hline & With impairment in reading & 315.00 & F81.0 \\
\hline & With impairment in written expression & 315.2 & F81.81 \\
\hline & With impairment in mathematics & 315.1 & F81.2 \\
\hline & Other Specified Attention-Deficit/Hyperactive Disorder & 314.01 & F90.8 \\
\hline & Unspecified Attention-Deficit/Hyperactivity Disorder & 314.01 & F90.9 \\
\hline & Developmental Coordination Disorder & 315.4 & F82 \\
\hline & Stereotypic Movement Disorder & 307.3 & F98.4 \\
\hline & Tic Disorders & & \\
\hline & Tourette's disorder & 307.23 & F95.2 \\
\hline & Persistent (Chronic) Motor or Vocal Tic Disorder & 307.22 & F95.1 \\
\hline & Provisional Tic Disorder & 307.21 & F95.0 \\
\hline & Other Specified Tic Disorder & 307.20 & F95.8 \\
\hline & Unspecified Tic Disorder & 307.20 & F95.9 \\
\hline
\end{tabular}




\begin{tabular}{|c|c|c|c|}
\hline Diagnostic Category & Diagnosis & DSM-5 Code & ICD-10 Code \\
\hline \multirow{8}{*}{$\begin{array}{l}\text { Schizophrenia Spectrum and Other } \\
\text { Psychotic Disorders }\end{array}$} & Delusional Disorder & 297.1 & F22 \\
\hline & Brief Psychotic Disorder & 298.8 & F23 \\
\hline & Schizophreniform Disorder & 295.40 & F20.81 \\
\hline & Schizoaffective Disorder & & \\
\hline & Bipolar type & 295.70 & F25.0 \\
\hline & Depressive type & 295.70 & F25.1 \\
\hline & Unspecified Schizophrenia Spectrum and Other Psychotic Disorder & 298.9 & F29 \\
\hline & Other Specified Schizophrenia Spectrum and Other Psychotic Disorder & 298.8 & F28 \\
\hline \multirow[t]{3}{*}{ Bipolar and Related Disorders } & Cyclothymic Disorder & 301.13 & F34.0 \\
\hline & Unspecified Bipolar and Related Disorder & 296.80 & F31.9 \\
\hline & Other Specified Bipolar and Related Disorder & 298.8 & F31.89 \\
\hline \multirow[t]{4}{*}{ Depressive Disorders } & Persistent Depressive Disorder (Dysthymia) & 300.4 & F34.1 \\
\hline & Premenstrual Dysphoric Disorder & 625.4 & N94.3 \\
\hline & Unspecified Depressive Disorder & 311 & F32.9 \\
\hline & Other Specified Depressive Disorder & 311 & F32.8 \\
\hline \multirow[t]{3}{*}{ Anxiety Disorders } & Selective Mutism & 313.23 & F94.0 \\
\hline & Unspecified Anxiety Disorder & 300.00 & F41.9 \\
\hline & Other Specified Anxiety Disorder & 300.09 & F41.8 \\
\hline \multirow{3}{*}{$\begin{array}{l}\text { Obsessive-Compulsive and Related } \\
\text { Disorders }\end{array}$} & Body Dysmorphic Disorder & 300.7 & F45.22 \\
\hline & Hoarding Disorder & 300.3 & F42 \\
\hline & Unspecified Obsessive-Compulsive and Related Disorder & 300.3 & F42 \\
\hline \multirow[t]{4}{*}{ Trauma- and Stressor-Related Disorders } & Adjustment Disorder & 309.x & F43.2x \\
\hline & Unspecified Trauma- and Stressor-Related Disorder & 309.9 & F43.9 \\
\hline & Other Specified Trauma- and Stressor-Related Disorder & 309.89 & F43.8 \\
\hline & Disinhibited Social Engagement Disorder & 313.89 & F94.2 \\
\hline \multirow[t]{3}{*}{ Dissociative Disorders } & Dissociative Identity Disorder & 300.14 & F44.81 \\
\hline & Unspecified Dissociative Disorder & 300.15 & F44.9 \\
\hline & Other Specified Dissociative Disorder & 300.15 & F44.89 \\
\hline \multirow{6}{*}{$\begin{array}{l}\text { Somatic Symptom and Related } \\
\text { Disorders }\end{array}$} & Conversion Disorder (Functional Neurological Symptom Disorder) & 300.11 & F44.x \\
\hline & Psychological Factors Affecting Other Medical Conditions & 316 & F54 \\
\hline & Factitious Disorder Imposed on Self & 300.19 & F68.10 \\
\hline & Factitious Disorder Imposed on Another & 300.19 & F68.10 \\
\hline & Unspecified Somatic Symptom and Related Disorder & 300.82 & F45.9 \\
\hline & Other Specified Somatic Symptom and Related Disorder & 300.89 & F45.8 \\
\hline \multirow[t]{5}{*}{ Feeding and Eating Disorders } & Bulimia Nervosa & 307.51 & F50.2 \\
\hline & Pica & 307.52 & F98.3 \\
\hline & Rumination Disorder & 307.53 & F98.21 \\
\hline & Unspecified Feeding or Eating Disorder & 307.50 & F50.9 \\
\hline & Other Specified Feeding or Eating Disorder & 307.59 & F50.8 \\
\hline \multirow[t]{4}{*}{ Elimination Disorders } & Unspecified Elimination Disorder with Urinary Symptoms & 788.30 & R32 \\
\hline & Other Specified Elimination Disorder with Urinary Symptoms & 788.39 & N39.498 \\
\hline & Unspecified Elimination Disorder with Fecal Symptoms & 787.60 & R15.9 \\
\hline & Other Specified Elimination Disorder with Fecal Symptoms & 787.60 & R15.9 \\
\hline
\end{tabular}




\begin{tabular}{|c|c|c|c|}
\hline Diagnostic Category & Diagnosis & DSM-5 Code & ICD-10 Code \\
\hline \multirow[t]{15}{*}{ Sleep-Wake Disorders } & Circadian Rhythm Sleep-Wake Disorder & 307.45 & G47.2x \\
\hline & Unspecified Insomnia Disorder & 780.52 & G47.00 \\
\hline & Other Specified Insomnia Disorder & 780.52 & G47.09 \\
\hline & Unspecified Hypersomnolence Disorder & 780.54 & G47.10 \\
\hline & Narcolepsy & 347.xx & G47.4xx \\
\hline & Breathing-Related Sleep-Wake Disorders & & \\
\hline & Obstructive Sleep Apnea Hypopnea & 327.23 & G47.33 \\
\hline & Central Sleep Apnea & 327.21 & G47.31 \\
\hline & Sleep-Related Hypoventilation & $327.2 \mathrm{x}$ & G47.3x \\
\hline & Parasomnias & & \\
\hline & Rapid Eye Movement Sleep Arousal Disorders, & & \\
\hline & Sleepwalking type & 307.46 & F51.3 \\
\hline & Sleep terror type & 307.46 & F51.4 \\
\hline & Nightmare Disorder & 307.47 & F51.5 \\
\hline & Rapid Eye Movement Sleep Behavior Disorder & 327.42 & G47.52 \\
\hline \multirow[t]{2}{*}{ Gender Dysphoria } & Unspecified Gender Dysphoria & 302.6 & F64.9 \\
\hline & Other Specified Gender Dysphoria & 302.6 & F64.8 \\
\hline \multirow{4}{*}{$\begin{array}{l}\text { Disruptive, Impulse-Control, and } \\
\text { Conduct Disorders }\end{array}$} & Pyromania & 312.33 & F63.1 \\
\hline & Kleptomania & 312.32 & F63.2 \\
\hline & Unspecified Disruptive, Impulse-Control, and Conduct Disorder & 312.9 & F91.9 \\
\hline & Other Specified Disruptive, Impulse-Control, and Conduct Disorder & 312.89 & F91.8 \\
\hline \multirow{3}{*}{$\begin{array}{l}\text { Substance-Related and Addictive } \\
\text { Disorders }\end{array}$} & Unspecified Alcohol-Related Disorder & 291.9 & F10.99 \\
\hline & Unspecified Cannabis-Related Disorder & 292.9 & F12.99 \\
\hline & Unspecified Tobacco-Related Disorder & 292.9 & F17.209 \\
\hline
\end{tabular}

Table 3. Validity indicators of diagnosing DSM-5 diagnostic categories using the CASDI.

\begin{tabular}{|c|c|c|c|c|c|c|c|c|c|}
\hline \multirow[t]{4}{*}{ CASDI } & \multicolumn{2}{|c|}{$\begin{array}{c}\text { DSM-5 } \\
\text { Pediatric } \\
\text { Interview }\end{array}$} & \multirow[t]{4}{*}{$\begin{array}{c}\text { Kappa } \\
\text { (SE) }\end{array}$} & \multirow[t]{4}{*}{$\begin{array}{l}\text { Sensitivity } \\
\text { 95\%CI } \\
\text { (\%) }\end{array}$} & \multirow[t]{4}{*}{$\begin{array}{l}\text { Specificity } \\
95 \% \mathrm{CI} \\
\text { (\%) }\end{array}$} & \multirow[t]{4}{*}{$\begin{array}{c}\text { Positive } \\
\text { Likelihood } \\
\text { Ratio } \\
\text { 95\%CI }\end{array}$} & \multirow[t]{4}{*}{$\begin{array}{c}\text { Negative } \\
\text { Likelihood } \\
\text { Ratio } \\
\text { 95\%CI }\end{array}$} & \multirow[t]{4}{*}{$\begin{array}{c}\text { Positive } \\
\text { Predictive } \\
\text { Value } \\
95 \% \text { I } \\
(\%) \\
\end{array}$} & \multirow[t]{4}{*}{$\begin{array}{c}\text { Negative } \\
\text { Predictive } \\
\text { Value } \\
95 \% \text { I } \\
\text { (\%) } \\
\end{array}$} \\
\hline & - & + & & & & & & & \\
\hline & $a$ & $b$ & & & & & & & \\
\hline & $c$ & $d$ & & & & & & & \\
\hline \multirow{2}{*}{$\begin{array}{l}\text { Neurodevelopmental } \\
\text { Disorders }\end{array}$} & 260 & 2 & \multirow{2}{*}{$\begin{array}{c}.88 \\
(.053)\end{array}$} & \multirow{2}{*}{$\begin{array}{c}90.91 \\
70.84-98.88\end{array}$} & \multirow{2}{*}{$\begin{array}{c}98.86 \\
96.70-99.76\end{array}$} & \multirow{2}{*}{$\begin{array}{c}79.70 \\
25.67-247.42\end{array}$} & \multirow{2}{*}{$\begin{array}{c}.09 \\
.02-.34\end{array}$} & \multirow{2}{*}{$\begin{array}{c}86.96 \\
66.41-97.22\end{array}$} & \multirow{2}{*}{$\begin{array}{c}99.24 \\
97.27-99.91\end{array}$} \\
\hline & 3 & 20 & & & & & & & \\
\hline \multirow{2}{*}{$\begin{array}{l}\text { Schizophrenia Spectrum } \\
\text { and Other Psychotic } \\
\text { Disorders }\end{array}$} & 282 & 0 & \multirow{2}{*}{$\begin{array}{c}.80 \\
(.197)\end{array}$} & \multirow{2}{*}{$\begin{array}{c}100.00 \\
15.81-100.00\end{array}$} & \multirow{2}{*}{$\begin{array}{c}99.65 \\
98.05-99.99\end{array}$} & \multirow{2}{*}{$\begin{array}{c}283.00 \\
40.00-2002.16\end{array}$} & \multirow{2}{*}{.00} & \multirow{2}{*}{$\begin{array}{c}66.67 \\
9.43-99.16\end{array}$} & \multirow{2}{*}{$\begin{array}{c}100.00 \\
98.70-100.00\end{array}$} \\
\hline & 1 & 2 & & & & & & & \\
\hline \multirow{2}{*}{$\begin{array}{l}\text { Bipolar and Related } \\
\text { Disorders }\end{array}$} & 276 & 2 & \multirow{2}{*}{$\begin{array}{l}.19 \\
(.170)\end{array}$} & \multirow{2}{*}{$\begin{array}{c}33.33 \\
.84-90.57\end{array}$} & \multirow{2}{*}{$\begin{array}{c}97.87 \\
95.43-99.22\end{array}$} & \multirow{2}{*}{$\begin{array}{c}15.67 \\
2.63-93.41\end{array}$} & \multirow{2}{*}{$\begin{array}{c}.68 \\
.31-1.52\end{array}$} & \multirow{2}{*}{$\begin{array}{c}14.29 \\
0.36-57.87\end{array}$} & \multirow{2}{*}{$\begin{array}{c}99.28 \\
97.43-99.91\end{array}$} \\
\hline & 6 & 1 & & & & & & & \\
\hline Depressive Disorders & 264 & 2 & .67 & 84.62 & 97.06 & 28.77 & .16 & 57.89 & 99.25 \\
\hline & 8 & 11 & $(.098)$ & $54.55-98.08$ & $94.29-98.72$ & $13.99-59.16$ & $.04-.57$ & $33.50-79.75$ & $97.31-99.91$ \\
\hline Anyiety Dicorderc & 265 & 4 & .73 & 75.00 & 98.51 & 50.44 & & 75.00 & \\
\hline Anxiety Disorders & 4 & 12 & $(.090)$ & $47.62-92.73$ & $96.24-99.59$ & $18.32-138.90$ & & $47.62-92.73$ & $96.24-99.59$ \\
\hline Obsessive-Compulsive and & 277 & 0 & .54 & 100.00 & 98.23 & 56.40 & 00 & 37.50 & 100.00 \\
\hline Related Disorders & 5 & 3 & $(.182)$ & $29.24-100.00$ & $95.91-99.42$ & 23.66-134.45 & & $8.52-75.51$ & $98.68-100.00$ \\
\hline Trauma- and Stressor- & 277 & 1 & .76 & 83.33 & 99.28 & 116.25 & .17 & 71.43 & 99.64 \\
\hline Related Disorders & 2 & 5 & $(.132)$ & $35.88-99.58$ & 97.43-99.91 & $27.92-484.11$ & $.03-1.00$ & $29.04-96.33$ & 98.01-99.99 \\
\hline Disse & 278 & 2 & .24 & 33.33 & 98.58 & 23.50 & .68 & 20.00 & 99.29 \\
\hline Dissociative Disorders & 4 & 1 & $(.204)$ & $.84-90.57$ & $96.41-99.61$ & $3.61-152.92$ & $.30-1.51$ & $.51-71.64$ & $97.44-99.91$ \\
\hline Somatic Symptom and & 275 & 1 & .45 & 75.00 & 97.86 & 35.12 & & 33.33 & 99.64 \\
\hline & 6 & 3 & $(.173)$ & $19.41-99.37$ & $95.41-99.21$ & $13.28-92.94$ & $.05-1.39$ & $7.49-70.07$ & $98.00-99.99$ \\
\hline
\end{tabular}




\begin{tabular}{|c|c|c|c|c|c|c|c|c|c|c|}
\hline \multirow[t]{4}{*}{ CASDI } & & \multicolumn{2}{|c|}{$\begin{array}{c}\text { DSM-5 } \\
\text { Pediatric } \\
\text { Interview }\end{array}$} & \multirow[t]{4}{*}{$\begin{array}{c}\text { Kappa } \\
\text { (SE) }\end{array}$} & \multirow[t]{4}{*}{$\begin{array}{c}\text { Sensitivity } \\
95 \% \mathrm{CI} \\
(\%)\end{array}$} & \multirow[t]{4}{*}{$\begin{array}{c}\text { Specificity } \\
95 \% \text { CI } \\
(\%)\end{array}$} & \multirow[t]{4}{*}{$\begin{array}{c}\text { Positive } \\
\text { Likelihood } \\
\text { Ratio } \\
\text { 95\%CI }\end{array}$} & \multirow[t]{4}{*}{$\begin{array}{c}\text { Negative } \\
\text { Likelihood } \\
\text { Ratio } \\
95 \% \text { CI }\end{array}$} & \multirow[t]{4}{*}{$\begin{array}{c}\text { Positive } \\
\text { Predictive } \\
\text { Value } \\
95 \% \text { CI } \\
(\%) \\
\end{array}$} & \multirow[t]{4}{*}{$\begin{array}{c}\text { Negative } \\
\text { Predictive } \\
\text { Value } \\
95 \% \text { CI } \\
\text { (\%) } \\
\end{array}$} \\
\hline & & - & + & & & & & & & \\
\hline & - & $a$ & $b$ & & & & & & & \\
\hline & + & $c$ & $d$ & & & & & & & \\
\hline \multirow{2}{*}{$\begin{array}{l}\text { Feeding and Eating } \\
\text { Disorders }\end{array}$} & & 281 & 0 & \multirow{2}{*}{$\begin{array}{c}.86 \\
(.143)\end{array}$} & \multirow{2}{*}{$\begin{array}{c}100.00 \\
29.24-100.00\end{array}$} & \multirow{2}{*}{$\begin{array}{c}99.65 \\
98.04-99.99\end{array}$} & \multirow{2}{*}{$\begin{array}{c}282.00 \\
39.86-1995.06\end{array}$} & \multirow{2}{*}{.00} & \multirow{2}{*}{$\begin{array}{c}75.00 \\
19.41-99.37\end{array}$} & \multirow{2}{*}{$\begin{array}{c}100.00 \\
98.70-100.00\end{array}$} \\
\hline & & 1 & 3 & & & & & & & \\
\hline \multirow{2}{*}{ Elimination Disorders } & & 283 & 0 & \multirow{2}{*}{$\begin{array}{l}1.00 \\
(.00)\end{array}$} & \multirow{2}{*}{$\begin{array}{c}100.00 \\
15.81-100.00\end{array}$} & \multirow{2}{*}{$\begin{array}{c}100.00 \\
98.70-100.00\end{array}$} & & \multirow{2}{*}{.00} & \multirow{2}{*}{$\begin{array}{c}100.00 \\
15.81-100.00\end{array}$} & \multirow{2}{*}{$\begin{array}{c}100.00 \\
98.70-100.00\end{array}$} \\
\hline & & 0 & 2 & & & & & & & \\
\hline \multirow{2}{*}{ Sleep-Wake Disorders } & & 273 & 2 & \multirow{2}{*}{$\begin{array}{c}.66 \\
(.131)\end{array}$} & \multirow{2}{*}{$\begin{array}{c}75.00 \\
34.91-96.81\end{array}$} & \multirow{2}{*}{$\begin{array}{c}98.56 \\
96.34-99.61\end{array}$} & \multirow{2}{*}{$\begin{array}{c}51.94 \\
18.14-148.71\end{array}$} & \multirow{2}{*}{$\begin{array}{c}.25 \\
.08-.84\end{array}$} & \multirow{2}{*}{$\begin{array}{c}60.00 \\
26.24-87.84\end{array}$} & \multirow{2}{*}{$\begin{array}{c}99.27 \\
97.40-99.91\end{array}$} \\
\hline & & 4 & 6 & & & & & & & \\
\hline \multirow{2}{*}{ Gender Dysphoria } & & 284 & 0 & \multirow{2}{*}{$\begin{array}{l}1.00 \\
(.00)\end{array}$} & \multirow{2}{*}{$\begin{array}{c}100.00 \\
2.50-100.00\end{array}$} & \multirow{2}{*}{$\begin{array}{c}100.00 \\
98.71-100.00\end{array}$} & & 00 & 100.00 & 100.00 \\
\hline & & 0 & 1 & & & & & .00 & $2.50-100.00$ & $98.71-100.00$ \\
\hline Disruptive, Impulse- & & 266 & 3 & .87 & 83.33 & 99.63 & 222.50 & .17 & 93.75 & 98.88 \\
\hline Disorders & & 1 & 15 & $(.062)$ & $58.58-96.42$ & $97.93-99.99$ & $31.12-1591.02$ & $.06-.47$ & $69.77-99.84$ & $96.78-99.77$ \\
\hline Substance-Related and & & 280 & 0 & .75 & 100.00 & 99.29 & 141.00 & $\Omega 0$ & 60.00 & 100.00 \\
\hline Addictive Disorders & & 2 & 3 & $(.173)$ & 29.24-100.00 & $97.46-99.91$ & $35.44-561.03$ & .00 & $14.66-94.73$ & $98.69-100.00$ \\
\hline
\end{tabular}

95\% CI, 95\% Confidence Intervals.

However, the rigidity of the CASDI rules and the inflexibility of the diagnostic algorithms hamper the detection of symptom hierarchical importance that can only be detected in unstructured interviews that are mostly based on clinical judgement. Another possible limitation is that the interviewer is obliged to rely on the respondent's assessment of whether a symptom is present or not, and each respondent may be using a scale of symptom severity that is different from that employed in clinical practice. For instance, it has been shown that children tend to overestimate the occurrence of rare phenomena that lie outside the realm of normal experience, such as manic or psychotic symptoms [20]. The possible child and adolescent interviewees' difficulty of understanding some items, and the lack of mechanisms to exclude misunderstanding and intentional or unintentional denial of symptoms as well as to verify the accuracy of recall of symptoms are also some of the CASDI limitations that the joint interview of both children and parents attempt to address to some extent. Finally, the need for some knowledge or clinical judgment capacity to identify some mental symptoms does not permit the administration of the CASDI by totally lay interviewers, even after strong training in the interview administration.

Overall, the CASDI has high validity (above 70\%) in diagnosing the great majority of child and adolescent mental health disorders in Greek population. However, we should be cautious when using it for bipolar disorders and dissociative disorders. The observed validity indicators suggest that the CASDI can potentially be used to accurately diagnose child and adolescent mental health disorders for research and clinical purposes. Its use in clinical samples and special populations, such as hospitalized or institutionalized children and adolescents, deserves further study.

\section{ETHICS APPROVAL AND CONSENT TO PARTICIPATE}

Not applicable.

\section{CONFLICT OF INTEREST}

The author confirms that this article content has no conflict of interest.

\section{ACKNOWLEDGEMENTS}

The author wishes to extend his sincere thanks to Mrs. Afroditi Prassou, Mrs. Maria Markoulaki and Mrs. Phaedra Kapodistria who participated in data collection. He also thanks staff members of municipal services who offered their valuable support during recruitment of the sample. Lastly, he is really thankful to children and adolescents who help him edit language of the CASDI and to all families that participated in the study with no material incentives.

\section{REFERENCES}


2013

[2] Leffler JM, Riebel J, Hughes HM. A review of child and adolescent diagnostic interviews for clinical practitioners. Assessment 2015; 22(6): 690-703.

[http://dx.doi.org/10.1177/1073191114561253] [PMID: 25520212]

[3] Kendell R, Jablensky A. Distinguishing between the validity and utility of psychiatric diagnoses. Am J Psychiatry 2003; $160(1)$ : 4-12. [http://dx.doi.org/10.1176/appi.ajp.160.1.4] [PMID: 12505793]

[4] Adamowska S, Adamowski T, Frydecka D, Kiejna A. Diagnostic validity Polish language version of the questionnaire MINI-KID (Mini International Neuropsychiatry Interview for Children and Adolescent). Compr Psychiatry 2014; 55(7): 1744-50. [http://dx.doi.org/10.1016/j.comppsych.2014.05.019] [PMID: 25023384]

[5] Cerel J, Fristad MA. Scaling structured interview data: a comparison of two methods. J Am Acad Child Adolesc Psychiatry 2001; 40(3): 341-6. [http://dx.doi.org/10.1097/00004583-200103000-00014] [PMID: 11288776]

[6] Lai KY, Leung PW, Mo FY, et al. Validation of the developmental, dimensional and diagnostic interview (3Di) among chinese children in a child psychiatry clinic in Hong Kong. J Autism Dev Disord 2015; 45(5): 1230-7. [http://dx.doi.org/10.1007/s10803-014-2284-6] [PMID: 25326822]

[7] Macleod E, Woolford J, Hobbs L, Gross J, Hayne H, Patterson T. Interviews with children about their mental health problems: The congruence and validity of information that children report. Clin Child Psychol Psychiatry 2016; 1359104516653642. [PMID: 27352797]

[8] Hilt RJ, Nussbaum AM. DSM-5 Pediatric Diagnostic Interview. In: Hilt RJ, Nussbaum AM, Eds. DSM-5 Pocket Guide for Child and Adolescent Mental Health. Arlington, VA: American Psychiatric Association Publishing 2016; pp. 74-115.

[9] Altman D, Machin D, Bryant T, Gardner M, Eds. Statistics with confidence. London: BMJ Books 2000.

[10] Fleiss J, Levin B, Cho Paik M. Statistical methods for rates and proportions. New York: John Wiley \& Sons 2003. [http://dx.doi.org/10.1002/0471445428]

[11] Komiti AA, Jackson HJ, Judd FK, et al. A comparison of the composite international diagnostic interview (CIDI-Auto) with clinical assessment in diagnosing mood and anxiety disorders. Aust N Z J Psychiatry 2001; 35(2): 224-30. [http://dx.doi.org/10.1046/j.1440-1614.2001.00868.x] [PMID: 11284905]

[12] Janca A, Robins LN, Cottler LB, Early TS. Clinical observation of assessment using the composite international diagnostic interview (CIDI). An analysis of the CIDI field trials wave II at the St louis site. Br J Psychiatry 1992; 160: 815-8. [http://dx.doi.org/10.1192/bjp.160.6.815] [PMID: 1617365]

[13] Jordanova V, Wickramesinghe C, Gerada C, Prince M. Validation of two survey diagnostic interviews among primary care attendees: a comparison of CIS-R and CIDI with SCAN ICD-10 diagnostic categories. Psychol Med 2004; 34(6): $1013-24$ [http://dx.doi.org/10.1017/S0033291703001727] [PMID: 15554572]

[14] Booth BM, Kirchner JE, Hamilton G, Harrell R, Smith GR. Diagnosing depression in the medically ill: validity of a lay-administered structured diagnostic interview. J Psychiatr Res 1998; 32(6): 353-60. [http://dx.doi.org/10.1016/S0022-3956(98)00031-4] [PMID: 9844951]

[15] Renou S, Hergueta T, Flament M, Mouren-Simeoni MC, Lecrubier Y. Diagnostic structured interviews in child and adolescents psychiatry. Encephale 2004; 30(2): 122-34.

[http://dx.doi.org/10.1016/S0013-7006(04)95422-X] [PMID: 15107714]

[16] Rosenman SJ, Korten AE, Levings CT. Computerised diagnosis in acute psychiatry: validity of CIDI-Auto against routine clinical diagnosis. J Psychiatr Res 1997; 31(5): 581-92. [http://dx.doi.org/10.1016/S0022-3956(97)00032-0] [PMID: 9368199]

[17] Quintana MI, Gastal FL, Jorge MR, Miranda CT, Andreoli SB. Validity and limitations of the brazilian version of the composite international diagnostic interview (CIDI 2.1). Rev Bras Psiquiatr 2007; 29(1): 18-22. [http://dx.doi.org/10.1590/S1516-44462006005000024] [PMID: 17435922]

[18] Lu J, Huang YQ, Liu ZR, Cao XL. Validity of chinese version of the composite international diagnostic interview-3.0 in psychiatric settings. Chin Med J (Engl) 2015; 128(18): 2462-6.

[http://dx.doi.org/10.4103/0366-6999.164930] [PMID: 26365963]

[19] Rijlaarsdam J, Stevens GW, van der Ende J, et al. Prevalence of DSM-IV disorders in a population-based sample of 5- to 8-year-old children: the impact of impairment criteria. Eur Child Adolesc Psychiatry 2015; 24(11): 1339-48. [http://dx.doi.org/10.1007/s00787-015-0684-6] [PMID: 25715995]

[20] Angold A, Costello EJ. The child and adolescent psychiatric assessment (CAPA). J Am Acad Child Adolesc Psychiatry 2000; 39 (1): 39-48. [http://dx.doi.org/10.1097/00004583-200001000-00015] [PMID: 10638066]

(C) George Giannakopoulos; Licensee Bentham Open

This is an open access article licensed under the terms of the Creative Commons Attribution-Non-Commercial 4.0 International Public License (CC BY-NC 4.0) (https://creativecommons.org/licenses/by-nc/4.0/legalcode), which permits unrestricted, non-commercial use, distribution and reproduction in any medium, provided the work is properly cited. 